\title{
FinTech Ecosystem as an Instrument of Sustainable Development Provision
}

\author{
Submitted 12/08/19, 1st revision 15/09/19, 2nd revision 23/10/19, accepted 21/11/19
}

\author{
N.G. Vovchenko ${ }^{1}$, S.S. Galazova ${ }^{2}$, A.A. Sopchenko ${ }^{3}$, O.S. Dzhu ${ }^{4}$
}

\begin{abstract}
:
Purpose: The article aims to determine the relationship between the FinTech ecosystem and ensuring a stable path of economic growth in the context of digitalization. The transition to digitalization of the financial sector is accompanied by a fundamentally new, qualitative transformation of socioeconomic relations in society.

Design/Methodology/Approach: As part of the study, the concept of FinTech was considered both in the context of technological innovation and in the context of companies utilizing these innovations in business, as well as the systematization of business models of the FinTech industry. The classification of horizontal and vertical innovations of the financial industry is given. The authors presented the structure of the FinTech ecosystem as an instrument for ensuring sustainable.

Findings: For the successful development of the FinTech ecosystem, the authors of the study presented a number of initiatives, the implementation of which will ensure the maintenance of the financial system stability, protection of consumer rights, as well as the digital innovations' development and implementation.

Practical Implications: The formation of a sustainable digital financial infrastructure tends to ensure the effective provision of services in the financial market, including for small and medium-sized companies, which will increase the availability of financial services and promote competition in the financial sector.

Originality/Value: The key contribution of the study is the ecosystem approach, which allowed determining the possibilities of safe sustainable development of the financial sector.
\end{abstract}

Keywords: Digitalization, FinTech, horizontal and vertical innovations.

JEL code: $G 23, O 32$.

Paper Type: Research article: FinTech.

\footnotetext{
${ }^{1}$ Professor, Department of Finance, Rostov State University of Economics, Rostov-on-Don, Russian Federation, nat.vovchenko@gmail.com

${ }^{2}$ Professor, Department of Economics, Khetagurov North Ossetian State University,

Vladikavkaz, Russian Federation

${ }^{3}$ Postgraduate, Department of Finance, Rostov State University of Economics, Rostov-on-

Don, Russian Federation, logvikova.anna@mail.ru

${ }^{4}$ Postgraduate, Rostov State University of Economics, Rostov-on-Don, Russian Federation, olga.dzhu@mail.ru
} 


\section{Introduction}

The global digitalization of economic processes is by far the most widely discussed topic in the world. The digital age achievements are capable of fundamentally changing not only the existing technologies, but also the relationships of all the levels between the state, business and citizens. The financial sector is one of the digitalization key drivers, while the financial technologies ecosystem acts as an integral tool in ensuring sustainable economic development. Digital ecosystems can become today a powerful factor in inclusive growth, contributing to economic and social integration, capturing all the sustainable development areas, such as: industrialization, innovation and infrastructure; sustainable cities and towns; partnership for sustainable development, etc., (Albekov et al., 2017; Vovchenko et al., 2017). The financial technologies development modernizes the financial and additional services' traditional areas, in which the innovative products and services for end users appear and also offers the prospect of accelerating the integration of the financial and real economies, expanding opportunities for greater decentralization in the transition to sustainable development.

In this regard, modern financial systems have a double task: first, to mobilize finances for the sustainable development specific priorities, and second, to take into account the sustainable development factors in the process of making financial decisions (UNCTAD, 2019).

\section{Materials and Methods}

Technological financial innovations offer already the sustainable development solutions within the following elements: intergenerational; social, economic and enviromental resilience; circularity; natural resource productivity solidarity; inclusive prosperity (Figure 1).

Figure 1. FinTech as a tool for sustainable development ${ }^{5}$

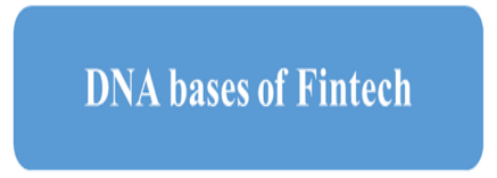

-Redefining accounting for value;

-Higher competition;

-Efficiency, speed and automation;

-Risk management and diversification;

-Transparency, accountability and collaboration;

-Accent and decentralization

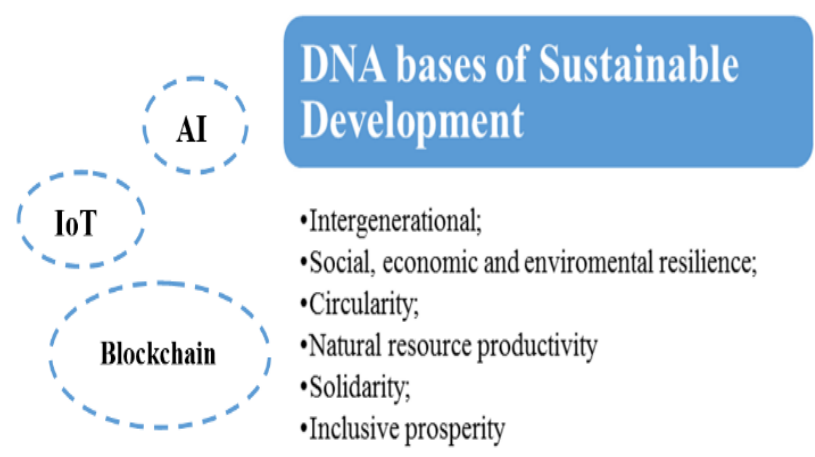

${ }^{5}$ Compiled by the authors based on: UNCTAD, 2019. 
It is often argued in modern discussions that technological advances can reduce the services cost and adapt such products as payments, transfers, insurance, credit or savings (deposits). It is assumed that innovations either create new products (horizontal innovations) or improve the current ones (vertical innovations) (Elsinger et al., 2018). Currently, most innovations in the financial industry can be seen as vertical innovations, as they increase and accelerate access to existing products and services, for example, financial account management, matching depositors and investors, managing payments, providing recommendations on choosing a portfolio or analyzing big data. However, some innovations, such as social bank accommodation (loans), can be seen as horizontal innovations (Japparova and Rupeika-Apoga, 2017).

\section{Results}

In the long-term development context, vertical innovation is the most important, that is, the improvement of existing innovative products with digital technologies. Figure 2 presents the Russian FinTech industry promising vertical innovations development forecast by 2035, the leading positions of which are: payments and transfers, financing, insurance, money management.

Figure 2. The promising FinTech segments development forecast in Russia by 2035 (Developed by the authors)

\section{Payments and transfers}

$96,3 \%$ of all transactions in Russia will be performed using innovative services for payments and transfers

\begin{tabular}{|c|c|}
\multicolumn{1}{|c|}{$\begin{array}{c}\text { VERTICAL } \\
\text { Insurance }\end{array}$} & financing \\
$\begin{array}{c}\mathbf{9 . 8 \%} \text { of all insurance premiums } \\
\text { will be paid to FinTech service } \\
\text { providers for insurance }\end{array}$ & $\begin{array}{c}\mathbf{4 6 . 1 \%} \% \text { of assets will be managed } \\
\text { by innovative services for } \\
\text { investment and money management }\end{array}$ \\
\hline
\end{tabular}

FinTech provides a significant part of the population with an access to a wide range of financial products. The factors determining demand and applied technologies are the basis for the FinTech industry formation. Changing consumer preferences stimulate the technology improvement, and technological progress is a key element in the consumer preferences' development. However, the pace of industry development also depends on the companies' access to finance and human capital and the regulatory effectiveness.

FinTech products are less expensive, more flexible and highly responsive. Conservative business structures significantly lose in terms of these characteristics, 
so there is a need for their adaptation to new realities. It should be noted that the term "FinTech" is used both to describe technological innovations ("FinTech") and the companies using these innovations ("FinTech"). FinTech is defined as software solutions for innovative products, services and processes in the financial industry, improving, complementing the existing offers in the financial services market. Consequently, FinTech companies are the companies which core business, core competencies and / or strategic focus is to develop these solutions.

It is necessary to note that FinTech companies are increasingly becoming an integral part of the financial industry. By providing the innovative solutions, they can support the existing financial institutions in their digital transformation. Technologies promoted by FinTechs are also very diverse. Although their categorization is still quite variable, they are often associated with the following areas: big data analytics (Polyakova et al., 2019); artificial intelligence (chat bots, machine learning); cryptography (for using cryptocurrency); technology of distributed registries (blockchain, Ethereum, R3 Corda.), etc. These technological transformations give rise to a new phase for the global financial system - Industry 4.0 .

The Industry 4.0 concept provides for the end-to-end digitalization of all the physical assets and their integration into the digital ecosystem along with the partners involved in the value chain. It corresponds to new digital technologies cloud services, mobile devices, augmented reality (portable gadgets), "Internet of things", geolocation (location determination), improved interfaces between an individual and a computer, authentication and others, 3D printing, artificial intelligence technologies, Big data analysis and advanced algorithms, personification by client profile. In this regard, we should consider the systematization of FinTech business models, which can be represented as cross-cutting innovations (Figure 3).

Figure 3. The cross-cutting FinTech innovations ${ }^{6}$
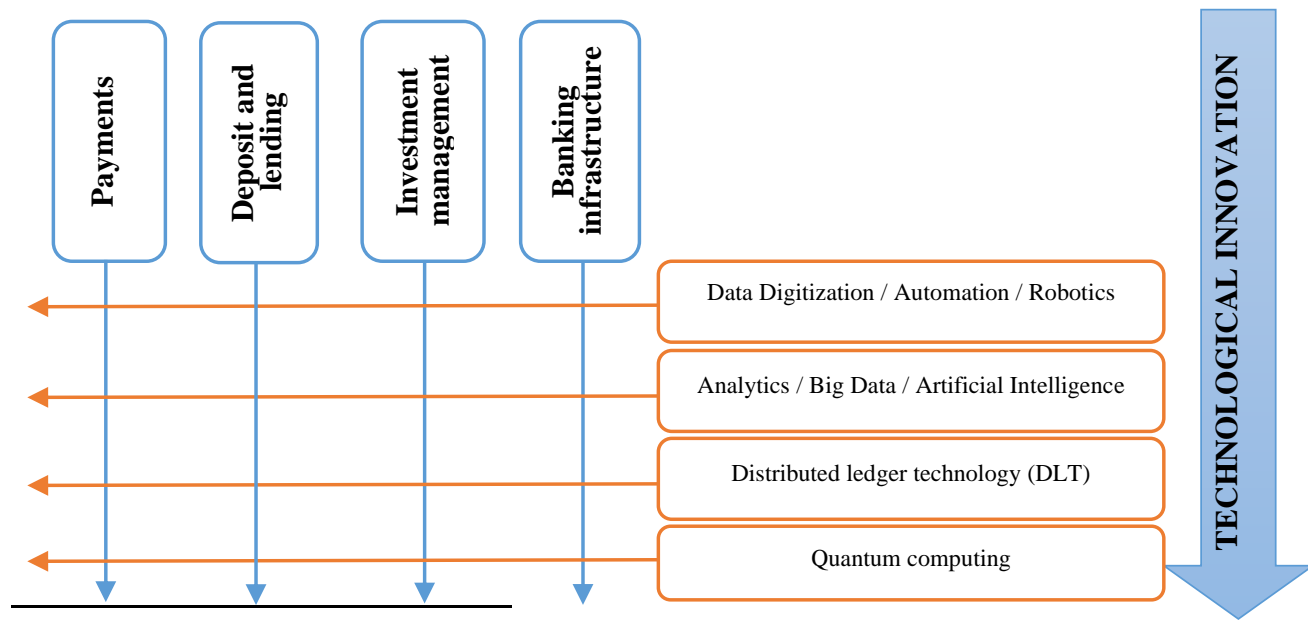

${ }^{6}$ Compiled by the authors based on: IFZ FinTech Study, 2019. 
FinTech end-to-end innovations should be understood as the key financial technologies that have the most significant impact on the development of both the financial system as a whole and financial markets and take into account two main aspects: scope (vertical axis) and technological orientation (horizontal axis). Using the presented structure, each FinTech company can be evaluated in two key aspects.

The technological measurement on the horizontal axis consists of several different categories: data digitization; automation; robotics; analytics; big data artificial intelligence; distributed ledger technology (DLT) and quantum computing. The orders indicate the degree of technological innovation and maturity. Secondary taxonomy also reflects the efficiency gains associated with cognitive automation to a certain extent. For example, Robotic Process Automation (RPA) is a part of the first level, while the applications with self-learning or optimization capabilities are the second level part.

The FinTech market development and the innovative products or services creating speed depend on the ecosystem formation and effective functioning. The financial technologies ecosystem should be understood as a structure ensuring the entities' interaction in the field of financial technologies for the innovative products and services creation and distribution in various economy areas.

In this study we identified the financial technologies ecosystem's key elements which are a set of interrelated factors such as demand, technology, access to finance, human capital and regulation, the effective functioning of which determines the vector of sustainable economic development both at the global level and in the Russian Federation (Figure 4).

Figure 4. The FinTech ecosystem key elements (Compiled by the authors)

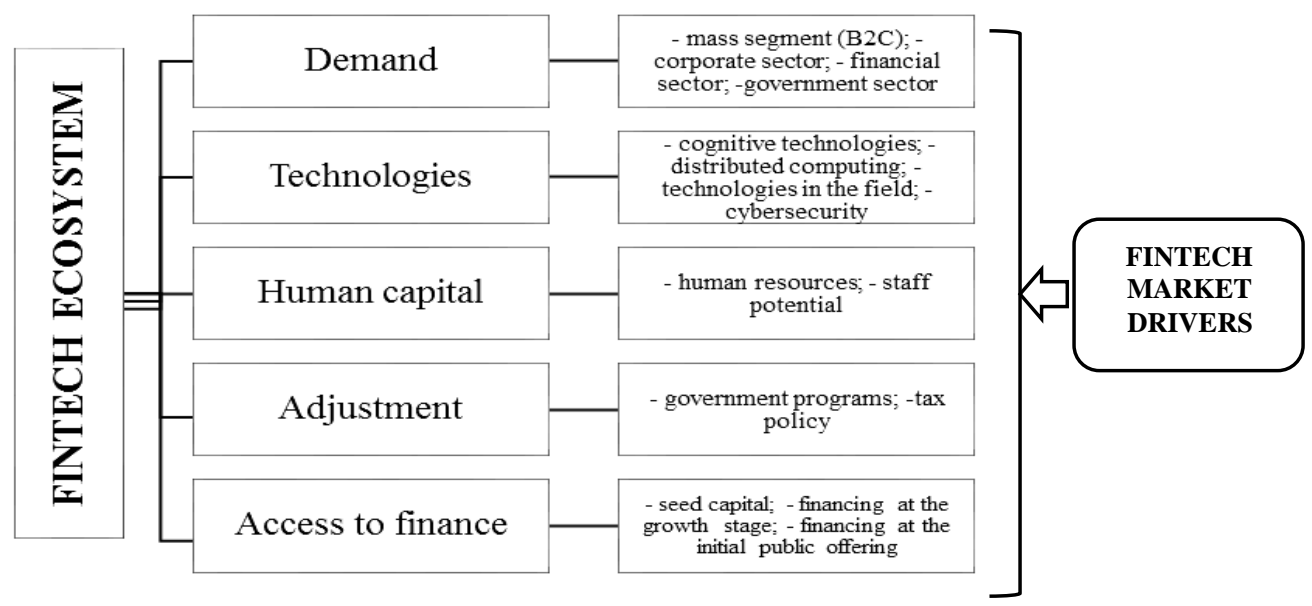


An access to financing at all stages is a prerequisite for the financial and technology companies' successful development and growth. In addition, the industry investments can increase its attractiveness for the increasing number of investors. Three key types of capital can be identified for FinTech companies, access to which determines the FinTech ecosystems' effectiveness:

1) Seed capital - investments at the earliest stage of the project. As a rule, young startups receive this type of financing from business angels, as well as through incubators and acceleration programs.

2) Growth capital - investments from the early development stage to the growth stage of FinTech companies. Financing of this type is provided by venture capital funds or corporate venture capital units.

3) Financing by the initial public offering (listed capital) of mature FinTech companies on the stock exchange.

The new roles of the future capable of challenging the traditional banking assumptions will emerge in the open ecosystem. A traditional bank should gradually move from the position of a "universal bank" to a position of a "universal partner" to support the customers that go beyond strictly banking products. This is a focus on a more useful, but less visible bank. Table 1 presents the new participants in the banking services market ecosystem.

Table 1. Some elements of a developed banking ecosystem ${ }^{7}$

\begin{tabular}{|l|l|}
\hline $\begin{array}{l}\text { New market } \\
\text { participants }\end{array}$ & Comment \\
\hline $\begin{array}{l}\text { Neobanks / } \\
\text { challenger banks }\end{array}$ & $\begin{array}{l}\text { Exclusively online banks (without a branch network) built on new } \\
\text { technology platforms. As a rule, neobanks offer higher interest } \\
\text { rates, lower level of commissions (or even their absence) and a } \\
\text { higher class of service and support. Without worthless stuff in the } \\
\text { form of outdated IT infrastructure, the new players have more } \\
\text { opportunities to create modern banking products. }\end{array}$ \\
\hline BigTechs & $\begin{array}{l}\text { Large technology companies that have an excessive influence, } \\
\text { including on the financial market (including: Google, Apple, } \\
\text { Facebook, Amazon). }\end{array}$ \\
\hline Retail & $\begin{array}{l}\text { Retail is the basis for the formation of the network interbank } \\
\text { relations that ensure the stability and efficiency of the banking } \\
\text { system }\end{array}$ \\
\hline Telecommunication & $\begin{array}{l}\text { With the use of communication technologies, the cost of customer } \\
\text { service is reduced, it becomes possible to flexibly manage loyalty, } \\
\text { increase mobility and transparency of internal processes }\end{array}$ \\
\hline
\end{tabular}

Some banks are already actively developing the ecosystem, giving their customers an opportunity to receive a variety of services, financial and non-financial on one platform. This creates an unprecedented competitive advantage and becomes one of

${ }^{7}$ Complied by the authors on the basis of EFMA, 2019. 
the powerful levers for increasing the banking business profitability. However, many banks still prefer to remain solely a bank, limiting their services to the basic banking products sale (CB RF, 2018).

Considering the Russian Federation experience, it is possible to observe a number of trends forming the prerequisites for stimulating and developing financial technologies, including: low margin of banking services; the transformation by the participants their business models' financial market and the desire to create the ecosystems; increased penetration of financial services by their digitalization; the loss of a monopoly on the traditional (payment and other) services provision by banks, as well as the acquisition by non-financial organizations of a significant role in the financial market; the desire of banks for partnerships with start-ups and technology companies.

In accordance with the research results, the most promising financial technologies are: Big Data and data analysis; mobile technology; Artificial Intelligence; Robotics biometrics; distributed registries; cloud technologies.

\section{Discussion and Conclusion}

Innovative digital solutions pose new risks for the consumers and the international finance entire system, which can lead to imbalances in the economy. For example, the FinTech platforms use implies the presence of operational and credit risks. Operational risk is associated with the functioning and uninterrupted operation of platforms and electronic systems, and credit risk may arise due to incorrect information about the borrower and his inability to fulfill his obligations. Of particular note is the high likelihood of realizing the risk of data confidentiality, information security and the risk of losing property rights that arise from the use of cloud and mobile services, face recognition technologies, social networks and geolocation data (Kuznetsov and Vovchenko, 2019).

For the effective and safe functioning of the digital financial space, it is necessary to implement the coordinated measures at all the participants level in the economic system as well as timely, proportional regulation, which will maintain the financial system stability, protecting the consumers' rights and promote the development and implementation of digital innovations (Saksonova and Kuzmina-Merlino, 2017.

Today, there is a transition from the digital technologies introduction to the integrated construction of a global digital ecosystem. This trend reflects the need for effective interaction between all the participants in the digitalization process government authorities, businesses, educational institutions, industrial enterprises and financial institutions. It is important to note that FinTech has global economic, social, and environmental implications regarding the policy issues of good governance and oversight. Figure 5 shows the structural and transitional effects of FinTech industry. 
Figure 5. FinTech's unintended consequences ${ }^{8}$

\begin{tabular}{|l|}
\hline STRUCTURAL \\
\hline Robo values \\
\hline Granular risk \\
\hline Cashless society \\
\hline Data and privacy \\
\hline Energy footprint \\
\hline Immutability \\
\hline Lack of analogue backups \\
\hline
\end{tabular}

\begin{tabular}{|l|}
\hline TRANSITIONAL \\
\hline Corruption killer apps \\
\hline Regulatory knowledge gaps widening \\
\hline Market Integrity in machine-driven markets \\
\hline Outsourcing risk to the unprepared \\
\hline Automation of employment \\
\hline Rise of cyber security risks \\
\hline Relationship commoditization \\
\hline
\end{tabular}

For the sustainable development of the FinTech business models presented in the study, the FinTech ecosystem creation and effective functioning is required. To do this, it is necessary to ensure the technologies and increased demand development for FinTech services and products by the adoption of comprehensive measures aimed at providing the financial and technological companies with an access to financing, as well as improving the regulatory environment and the training process. Thus, it seems necessary to determine the possibilities of the financial sector safe sustainable development in the context of digitalization, these include:

- the technology adoption stimulation by the regulators to increase the financial markets transparency;

- providing a wide range of financial services for small and medium-sized businesses within the framework of digital platforms;

- toughening the financial system regulation, protecting the rights of the financial services consumers, improving control by the state bank and increasing the sector stability on this basis;

- the programs implementation to improve the financial literacy of the population;

- a high level of training in the field of ICT, the development of competencies necessary for the financial technologies' development and implementation; - open access for foreign investors to financial instruments.

The presented initiatives give a synergistic effect for the FinTech development and the implementation of sustainable development areas, such as: quality education; decent work and economic growth; industrialization, innovation and infrastructure; inequality reduction; sustainable cities and towns; responsible consumption and production; effective development institutions; partnership for sustainable development, etc.

\footnotetext{
${ }^{8}$ Complied by the authors on the basis of: IEH, 2019.
} 


\section{References:}

Albekov, U.A., Vovchenko, N., Andreeva, G., Vladimirovna, O. and Sichev, R.A. 2017. Block Chain and Financial Controlling in the System of Technological Provision of Large Corporations. European Research Studies Journal, 20(3B), 3-12.

CB RF. 2018. The main financial technologies development directions for the period 2018 2020. Central Bank of the Russian Federation.

Efma. 2019. World FinTech Report. Available at: https://www.efma.com/study/detail/31138

Elsinger, H., Fessler, P., Feyrer, J., Konrad Richter, Silgoner, M., Timel, A. 2018.

Digitalization in financial services and household finance: FinTech, financial literacy and financial stability. Financial Stability Report, 35, 50-58.

IEH. 2019. Fintech and Sustainable Development: Assessing the Implications. Inquiry:

Design of a Sustainable Financial System, Geneva, Switzerland, International Environment House.

IFZ FinTech Study. 2019. An Overview of Swiss FinTech. Institute of Financial Services Zug IFZ, available at: https://blog.hslu.ch/retailbanking/files/2019/03/IFZ-FinTechStudy-2019_Switzerland.pdf

Japparova, I. and Rupeika-Apoga, R. 2017. Banking Business Models of the Digital Future: The Case of Latvia. European Research Studies Journal, 20(3A), 846-860.

Kuznetsov, N.G., Vovchenko, N.G. 2019. Digital Transformation of the Russian Economy: Development Path: Monograph. Rostov-on-Don, RSUE Publishing, 319.

Polyakova, A.G., Loginov, M.P., Serebrennikova, A.I., Thalassinos, E.I. 2019. Design of a socio-economic processes monitoring system based on network analysis and big data. International Journal of Economics and Business Administration, 7(1), 130-139.

Saksonova, S. and Kuzmina-Merlino, I. 2017. Fintech as Financial Innovation - The Possibilities and Problems of Implementation. European Research Studies Journal, 20(3A), 961-973.

UNCTAD. 2019. Digital services and sustainable finance. UNCTAD Multi-year Expert Meeting on TRADE, SERVICES AND DEVELOPMENT, enhancing productive capacity through services, Geneva, 1-2 May, available at: https://unctad.org/meetings/en/Presentation/c1mem42019_11_Kern.pdf

Vovchenko, G.N., Andreeva, V.A., Orobinskiy, S.A. and Filippov, M.Y. 2017. Competitive Advantages of Financial Transactions on the Basis of the Blockchain Technology in Digital Economy. European Research Studies Journal, 20(3B), 193-212. 